\title{
ROBERT GARNIER, Hippolyte (1573). La Troade (1579)
}

\section{Michele Mastroianni}

\section{OpenEdition \\ Journals}

\section{Edizione digitale}

URL: https://journals.openedition.org/studifrancesi/44923

DOI: 10.4000/studifrancesi.44923

ISSN: 2427-5856

\section{Editore}

Rosenberg \& Sellier

\section{Edizione cartacea}

Data di pubblicazione: 1 août 2021

Paginazione: 362-363

ISSN: 0039-2944

\section{Notizia bibliografica digitale}

Michele Mastroianni, «Robert garnier, Hippolyte (1573). La Troade (1579)», Studi Francesi [Online], 194 (LXV | II) | 2021, online dal 01 septembre 2021, consultato il 15 octobre 2022. URL: http://

journals.openedition.org/studifrancesi/44923 ; DOI: https://doi.org/10.4000/studifrancesi.44923

Questo documento è stato generato automaticamente il 15 octobre 2022.

\section{(c)}

Creative Commons - Attribuzione - Non commerciale - Non opere derivate 4.0 Internazionale - CC BYNC-ND 4.0

https://creativecommons.org/licenses/by-nc-nd/4.0/ 


\title{
ROBERT GARNIER, Hippolyte (1573). La Troade (1579)
}

\author{
Michele Mastroianni
}

\section{NOTIZIA}

ROBERT GARNIER, Hippolyte (1573). La Troade (1579), éd. critique par J.-D. Beaudin, Paris, Classiques Garnier, 2019, «Classiques Jaunes» 694, 618 pp.

1 Studioso del teatro francese rinascimentale, Jean-Dominique Beaudin ripropone, dopo l'edizione di Hippolyte del 2009 per i Classiques Garnier e l'edizione della Troade, uscita anch'essa per i Classiques Garnier nel 2018 all'interno del Théâtre Complet di Robert Garnier, queste due tragedie di cui cura le edizioni. Precedute da un'introduzione piuttosto densa e certamente precisa per i dati e per le analisi condotte, Beaudin si sofferma sulla questione delle fonti di queste riscritture tragiche moderne, portando all'attenzione dello studioso del teatro cinquecentesco le riprese strutturali e contenutistiche dai modelli antichi greco-latini, da Euripide a Seneca in particolare. Si tratta, come noto alla critica specialistica, di pièces che costituiscono esempi di rielaborazioni tragiche nella Francia moderna del pieno Rinascimento di indubbio interesse storico da un lato, storiografico e critico dall'altro. Di certo uno degli interessi maggiori risiedono nella tecnica traduttiva di Garnier che, per primo, adatta la fonte classica antica piegandola a un indubbio esercizio di stile in lingua francese. Ciò è senz'altro vero per Hippolyte, la cui fabula Garnier riprende e riscrive a tratti tenendo sotto mano la tragedia di Euripide e quella di Seneca. Prima di Garnier tale storia mitica venne trattata e riadattata da due drammaturghi italiani quali Ottaviano Zara, autore di un Hippolito uscito a Padova nel 1558 e Coriolanus Martiranus che scrisse un Hippolitus pubblicato a Napoli nel 1563. Secondo Beaudin, Garnier tralascia le due tragedie italiane («Garnier les a négligées, faute peut-être de les avoir lues»), mentre sottolinea il prestito notevolissimo dalla Phodra di Seneca che - sostiene Beaudin - Garnier «imite directement, avec des transpositions, des amplifications, et sans renoncer à innover». Tuttavia l'editore moderno chiarisce giustamente che l'esercizio di Robert Garnier sulla 
fonte latina non è riconducibile a un lavoro di imitazione fedele quanto piuttosto ad una rielaborazione del modello antico in una direzione di costruzione tragica infedele o libera, «cinq scènes, ainsi que deux longs fragments du deuxième acte, ce qui n'est pas négligeable, ne proviennent pas de la tragédie latine; leur originalité prouve la liberté que Garnier manifeste à l'égard de son modèle». L'esercizio retorico ed esegetico soggiace, come noto, alla tecnica traduttiva rinascimentale che necessariamente doveva anche rispondere ai dibattiti teorici intorno al dépassement delle fonti classiche, in nome di una concezione di tragico moderno teorizzata all'interno dei débats cinquecenteschi europei e oggettivata nella prassi in seno alle riscritture cinquecentesche del teatro tragico greco-latino. Una stessa proceduralità strutturale ed ideologicamente congegnata da Robert Garnier è riscontrabile anche nella Troade il cui primo atto e il secondo uniti a due passaggi del terzo e alla quasi totalità del quarto atto - stando a quanto rilevato da J.-D. Baudin - danno prova di una rilettura e riscrittura della fabula classica, saccheggiata in larga parte dall'Ecuba e dalle Troadi di Euripide che viene attualizzato secondo una ricontestualizzazione rinascimentale, la quale ha come sfondo una riflessione politica desunta dal quadro delle guerre civili e di religione che politicamente, sociologicamente e teologicamente almeno spaccano l'Europa del XVI secolo.

2 Le due edizioni critiche sono precedute da ampie introduzioni (52 pp. nel primo caso e 36 pp. nel secondo), corredate di glossario e di un apparato critico sulla base di notazioni filologiche che consolidano il lavoro in una prospettiva scientifica di pregio. Resta una costatazione. Se la scelta dell'editore moderno verte sul proporre una bibliografia di base o quantomeno succinta, non si può però non notare che non sono stati citati, mai e in nessun caso, lavori importanti condotti sul versante della critica italiana. Se non si tratta di difficoltà di accesso alla lingua italiana, si tratterebbe forse di ignoranza rispetto a lavori che da tempo vengono condotti da studiosi in Italia e che ancora in Italia procedono con una certa rilevanza sia numerica sia qualitativa. La qual cosa balza certamente all'occhio. Grave è di certo, per chi si occupi di campi in cui gli studi critici non mancano oltre il territorio d'oltralpe. Si tratterà forse di una nuova, meglio, recente forma di anti-italianismo in atto? 